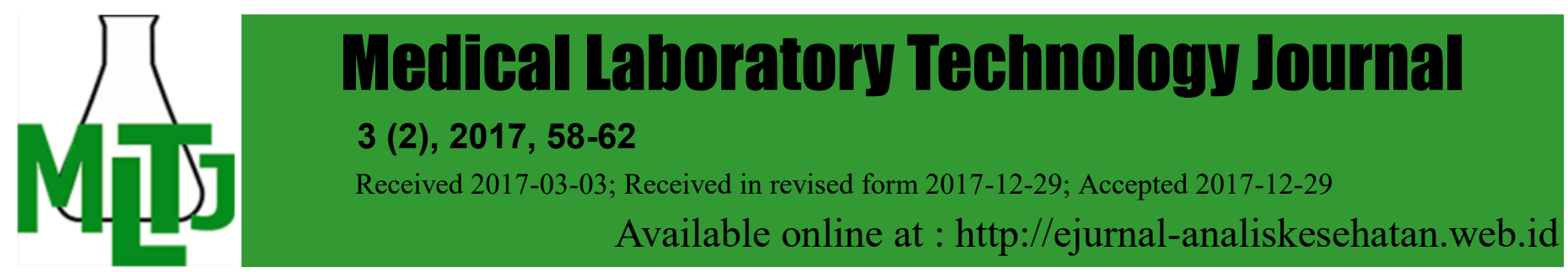

\title{
PEDICULOSIS CAPITIS DAN PERSONAL HYGIENE PADA ANAK SD DI DAERAH PEDESAAN KOTAMADYA BANJARBARU
}

\author{
Rifqoh, Wahdah Norsiah \\ Jurusan Analis Kesehatan Poltekkes Kemenkes Banjarmasin \\ JI Mistar Cokrokusumo 4a Banjarbaru \\ e-mail: rif.mayasin@gmail.com
}

\begin{abstract}
Pediculosis capitis or head lice infestation caused by Pediculus humanus var. capitis. Its caused irritation and scalp pruritus. Its occurs most commonly in children becaused they couldn't keep their personal hygiene independently. Pediculosis capitis caused disconcentrated, lack of sleep, parental anxiety, social embarrassment and isolation. The objective of this study was to determine the correlation between Pediculosis capitis with personal hygiene in rural primary schoolchildren in Cempaka Village, Banjarbaru Municipality. This analytic observational case control study design, at first determined $33(19,87 \%)$ schoolchildren was infested pediculosis capitis from 166 population. Other 33 schoolchildren randomized uninfested pediculosis capitis as the controls group (1:1 to case group). Pediculosis capitis was known by identified head lice, nymph or eggs of Pediculus humanus var. capitis and personal hygiene was measured by questionnaire. Chi Square test result, there was significant moderate positive correlation between pediculosis capitis with personal hygiene ( $p$ value $<0.001$ and $r=0,516$ ). Improved hair hygiene and avoid shared private tool like comb or other hair accesories as strategies for effective control pediculosis were recommended.
\end{abstract}

Keywords: pediculosis capitis; personal hygiene

Abstrak: Pediculosis capitis adalah infestasi kulit rambut kepala oleh Pediculus humanus var. capitis, mengakibatkan rasa gatal dan iritasi pada kulit kepala. Anak-anak adalah populasi yang paling sering terinfestasi Pediculosis capitis, dikarenakan anak-anak belum mampu secara mandiri melakukan kebersihan diri dan kebersihan lingkungan. Penyakit ini dapat menyebabkan gangguan tidur dan konsentrasi, kecemasan pada anak, perasaan malu bahkan dikucilkan dari pergaulan sosial. Penelitian ini bertujuan untuk mengetahui hubungan Pediculosis capitis dengan personal hygiene pada anak SD di Desa Cempaka Kotamadya Banjarbaru. Jenis penelitian ini adalah observasional analitik dengan desain Case Control. Besar sampel kelompok kasus dalam penelitian ini ditentukan berdasarkan jumlah kasus Pediculosis capitis yaitu 33 sampel $(19,87 \%)$ dari 166 total populasi. Kelompok kontrol ditentukan dengan perbandingan 1:1 terhadap kelompok kasus, yaitu 33 sampel, diambil secara random sampling. Data Pediculosis capitis dikumpulkan dari hasil identifikasi kutu dewasa, nimfa ataupun telur Pediculus humanus var. capitis dan Personal Hygiene dari hasil kuesioner. Hasil uji Chi Square didapatkan adanya hubungan antara Pediculosis capitis dengan personal hygiene dengan signifikansi $<0.001$ dan nilai korelasi 0,516 menunjukkan hubungan tingkat kekuatan hubungan sedang. Disarankan agar meningkatkan kebersihan rambut sehingga penyebab penularan kutu kepala dapat dihilangkan serta menghindari pemakaian alat pribadi secara bersama seperti sisir, kerudung, aksesoris rambut, dan sebagainya.

Kata kunci: pediculosis capitis; personal hygiene 


\section{PENDAHULUAN}

Pediculosis capitis adalah infestasi kutu kepala yang merupakan ektoparasit pada rambut dan kulit kepala manusia. Penyebab Pediculosis capitis adalah parasit kutu kepala species Pediculus humanus var capitis (Anoplura: Pediculidae) yang menghisap darah manusia untuk perkembangan hidupnya. Walaupun Pediculosis capitis bukanlah penyakit yang wajib dilaporkan atau bukan masalah kesehatan masyarakat utama dan belum pernah dilaporkan adanya vectorborne disease akibat Pediculosis capitis, namun penyakit ini dapat menyebabkan gangguan tidur dan konsentrasi pada anak bahkan dikucilkan dari pergaulan social (Madke and Khopkar, 2012).

Prevalensi dan insidensi Pediculosis capitis di seluruh dunia cukup tinggi dan bervariasi, baik di negara berkembang maupun negara maju. Di negara Turki prevalensi berkisar 0,7-59\%, di Eropa 0,48$22,4 \%$, di Inggris mencapai $37,4 \%$, di Australia mencapai $13 \%$, di Afrika mencapai $58,9 \%$ bahkan di Amerika prevalensi berkisar $3,6-61,4 \%$. Meskipun demikian penelitian prevalensi dan insidensi Pediculosis capitis sangat sedikit sehingga prevalensi yang pasti belum diketahui (Guenther, n.d.)

Pediculosis capitis perlu mendapat perhatian karena penyakit ini sering menyerang anak-anak umur 5-16 tahun, dimana pada usia tersebut adalah usia untuk mendapatkan pendidikan dasar Salah satu faktor Pediculosis capitis adalah personal hygiene yaitu suatu tindakan seseorang untuk memelihara kebersihan dan kesehatan dirinya untuk memperoleh kesejahteraan fisik dan psikologis. personal hygiene bertujuan antara lain mencegah timbulnya penyakit, meningkatkan percaya diri seseorang, dan menciptakan keindahan diri individu meliputi kebersihan kulit dan kebersihan rambut (Gulgun et al., 2013).

Pediculosis capitis yang tidak diobati dapat menimbulkan berbagai dampak pada penderitanya, antara lain berkurangnya kualitas tidur anak pada malam hari akibat rasa gatal, sehingga konsentrasi anak dalam belajar terganggu. Masalah lainnya adalah stigma sosial, rasa malu dan rendah diri terhadap teman-temannya. Selain itu di beberapa negara, sekolah menerapkan "Nonits Policy" yaitu siswa dengan Pediculosis capitis tidak diperbolehkan hadir di sekolah sehingga menyebabkan banyaknya ketidakhadiran anak di sekolah (Wolff et al., 2008)

Penelitian Pediculosis capitis di Indonesia juga masih belum banyak, beberapa penelitian antara lain (Zhen et al., n.d.) pada daerah perkotaan di Yogyakarta, $12,3 \%$ anak sekolah dasar terinfestasi Pediculosis capitis, sedangkan penelitian (Munusamy et al., n.d.), pada daerah pedesaan di Yogyakarta, 19,6\% anak sekolah dasar terinfestasi Pediculosis capitis. Penelitian lainnya oleh (Ansyah, 2013) menyatakan terdapat hubungan antara personal hygiene dengan kejadian Pediculosis capitis pada santri putri Pondok Pesantren Modern Islam Assalam Surakarta. Hasil penelitian pendahuluan pada anak SD di Desa Cempaka Banjarbaru, didapatkan $19,87 \%$ siswa terinfestasi Pediculosis capitis. Salah satu faktor yang mempengaruhi Pediculosis capitis pada anak SD adalah personal hygiene. Penelitian ini bertujuan untuk mengetahui hubungan Pediculosis capitis dengan personal hygiene pada anak SD di Desa Cempaka Banjarbaru.

\section{BAHAN DAN METODE}

Jenis penelitian yang dilakukan merupakan penelitian observasional analitik, dengan pendekatan case control yang bertujuan untuk mengetahui ada tidaknya hubungan infestasi kutu kepala (Pediculosis capitis) dengan personal hygiene pada anak SD di Desa Cempaka Banjarbaru.

Populasi dalam penelitian ini adalah seluruh anak SD di Desa Cempaka Banjarbaru yang berjumlah 166 orang. Jumlah sampel penelitian ini adalah 66 orang/responden, terdiri dari 33 responden sampel kelompok kasus dan 33 responden sampel kelompok kontrol.

Penentuan jumlah sampel kelompok kasus berdasarkan jumlah kasus anak yang terinfestasi kutu kepala (Pediculosis capitis) yaitu sebesar 33 orang. Jumlah kelompok kontrol ditentukan berdasarkan jumlah anak yang tidak terinfestasi kutu kepala (Pediculosis capitis) dengan perbandingan 1:1 terhadap jumlah kelompok kasus yaitu sebesar 33 orang. Pengambilan sampel kelompok kontrol dilakukan dengan cara random sampling. 
Kriteria inklusi responden penelitian ini adalah anak SD di Desa Cempaka Banjarbaru yang bersedia menjadi responden dan mengikuti proses pengambilan spesimen kutu kepala serta tidak terdapat luka atau trauma kepala. Sampel kelompok kasus adalah anak yang positif $(+)$ terinfestasi Pediculosis capitis. Kelompok kontrol adalah anak yang negatif (-) terinfestasi Pediculosis capitis yang ditentukan secara acak (random sampling) perbandingan 1:1 terhadap kelompok kasus.

Kriteria eksklusi responden penelitian ini adalah anak SD di Desa Cempaka Banjarbaru yang tidak bersedia menjadi responden dan mengikuti proses pengambilan spesimen kutu kepala, terdapat luka atau trauma kepala serta anakyang negatif (-) infestasi Pediculosis capitis yang tidak termasuk dalam sampel kelompok kontrol.

Instrumen yang dipergunakan dalam penelitian ini adalah identifikasi kutu kepala Pediculus capitis (alat: sisir rapat/serit, wadah sampel (plastik klip), label, kaca pembesar (loupe) dan mikroskop) dan kuesioner untuk data personal hygiene.

Persiapan penelitian; (1) observasi pendahuluan, (2) persiapan instrument penelitian, (3) penyusunan proposal, (4) uji Ethical, (5) perizinan, (6) sosialisasi penelitian dan (7) Persetujuan responden penelitian. Pelaksanaan penelitian; (1) pengisian kuesioner dan validasi melalui wawancara, (2) pengambilan specimen hasil penyisiran rambut kepala dan (3) pemeriksaan spesimen dan identifikasi telur, nimfa dan atau kutu kepala.

Pengolahan data meliputi; (1) editing data, (2) skoring kuesioner sebagai berikut: (a) Jika jawaban selalu skor 1, (b) Jika jawaban kadang-kadang skor 2, (c) Jika jawaban skor 3. Kriteria pengukuran personal hygiene sebagai berikut: (a) Baik skor nilai 41 - 60 dan (b) Kurang baik skor nilai 20 - 40. Analisis data menggunakan statistik non parametrik Chi Square dengan a 0,05

\section{HASIL DAN PEMBAHASAN}

Subjek penelitian ini adalah 66 orang, terdiri dari terdiri dari 28 laki-laki $(42,4 \%)$ dan 38 perempuan $(57,6 \%)$. Responden berumur antara 7 - 13 tahun. Pada gambar 1 menunjukkan sebagian besar responden berusia 10 tahun sebanyak 22 orang $(33,3 \%)$.

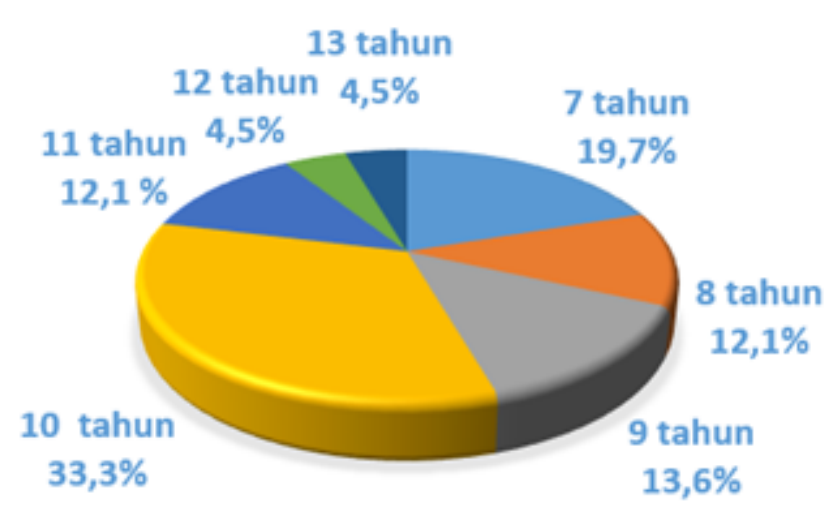

Gambar 1. Diagram Distribusi Umur Responden

Personal hygiene anak SD di Desa Cempaka Banjarbaru dari 66 responden kelompok kasus dan kelompok kontrol, didapatkan hasil 35 responden (53\%) dengan kategori baik dan 31 responden (47\%) dengan kategori kurang baik. Dari 66 orang subjek penelitian ini terdiri dari 33 positif Pediculosis capitis $(50 \%)$ sebagai kelompok kasus dan 33 negatif Pediculosis capitis (50\%) sebagai kelompok kontrol.

Tabulasi silang antara personal hygiene dengan Infestasi Pediculosis capitis pada responden menunjukkan bahwa responden yang mempunyai personal hygiene yang baik lebih sedikit prosentase Infestasi Pediculosis capitis yaitu $10,6 \%$ sedangkan responden yang mempunyai personal hygiene yang kurang baik prosentase Infestasi Pediculosis capitis lebih besar yaitu 39,4\% (Tabel 1).

Tabel 1. Tabulasi Silang Personal Hygiene dan Pediculosis capitis

\begin{tabular}{ccccc}
\hline & \multicolumn{4}{c}{ Personal Hygiene } \\
\cline { 2 - 5 } Jenis & \multicolumn{2}{c}{ Baik } & \multicolumn{3}{c}{ Kurang Baik } \\
Kelamin & $\mathrm{n}$ & $\%$ & $\mathrm{n}$ & $\%$ \\
\hline Positif & 7 & 10.6 & 26 & 39.4 \\
Negatif & 24 & 36.4 & 9 & 13.6 \\
\hline & 31 & 47 & 35 & 53 \\
\hline
\end{tabular}


Hasil uji statistik Chi Square menunjukkan nilai sig. sebesar $<0.001$ lebih kecil dari nilai a 0,05 dengan kekuatan korelasi 0,516. Hal ini menunjukkan bahwa terdapat hubungan positif antara personal hygiene dengan Infestasi Pediculosis capitis dengan kekuatan sedang.

Berdasarkan hasil penelitian 33 responden kelompok kasus atau positif Pediculosis capitis, kelompok umur terbesar adalah umur 10 tahun yaitu sebanyak 10 responden (15,2\%) Hasil ini didukung dengan penelitian (Saputri and Suryani, 2017) dimana kelompok umur 12 tahun merupakan yang tertinggi mengalami infestasi Pediculosis yaitu sebesar $84 \%$, namun berbeda dengan Caunahan (2004) yang menyatakan prevalensi terbanyak terjadi pada umur $<7$ tahun. Hal ini bisa terjadi karena adanya infestasi Pediculosis tergantung dengan tingkat kesadaran responden untuk menjaga kebersihan dirinya.

Berdasarkan hasil penelitian dari 33 responden kelompok kasus atau positif Pediculosis capitis terdiri dari 8 responden $(13 \%)$ berjenis kelamin laki-laki dan 25 responden $(37 \%)$ berjenis kelamin perempuan. Sedangkan pada kelompok kontrol atau negatif Pediculosis capitis, 33 responden terdiri dari 20 responden (30\%) berjenis kelamin laki-laki dan 13 responden $(20 \%)$ berjenis kelamin perempuan. Walaupun Pediculosis dapat menyerang siapa saja, namun perempuan dua kali lebih besar terkena Pediculosis dibandingkan lakilaki, karena perempuan lebih sering bertukar aksesoris rambut dan perempuan senang memiliki rambut yang panjang.

Berdasarkan Tabel 1., dari 33 responden kelompok kasus positif Pediculosis capitis, 7 responden $(10,6 \%)$ mempunyai Personal Hygiene yang baik dan 26 responden $(39,4 \%)$ mempunyai Personal Hygiene yang kurang baik sedangkan dari 33 responden kelompok kontrol, 24 responden (36,4\%) mempunyai Personal Hygiene yang baik dan 9 responden $(13,6 \%)$ mempunyai Personal Hygiene yang kurang baik.

Higiene perorangan atau yang biasa disebut dengan kebersihan diri adalah suatu tindakan yang dilakukan seseorang untuk memelihara kebersihan dan kesehatan dirinya untuk memperoleh kesejahteraan fisik dan psikologis. Pediculosis mudah menyerang anak sekolah karena anak-anak tidak terlalu serius memperhatikan kebersihan tubuhnya. Adanya infestasi Pediculosis sangat erat hubungannya dengan tingkat kesadaran responden untuk menjaga kebersihan dirinya, dimana kurangnya kesadaran untuk menjaga higiene pribadi dapat meningkatkan resiko terjadinya infestasi Pediculosis (Alatas, 2013)

Prevalensi Pediculosis terbanyak terjadi pada kelompok responden yang memiliki rambut panjang, hal ini mungkin terjadi karena kutu rambut lebih senang bersembunyi ditempat yang lembab rambut yang panjangnya melewati bahu akan mempermudah penularan infestasi Pediculosis. Rambut yang terlalu panjang pada wanita merupakan salah satu faktor yang menunjang terjadinya infestasi Pediculosis adalah higiene perorangan yang buruk seperti rambut yang relatif susah dibersihkan (Borges-Moroni et al., 2011).

Perilaku tidur bersama (orang tua, kakak dan/atau adik) merupakan yang tertinggi mengalami infestasi Pediculosis yaitu sebesar 10,5\% (13 dari 33 responden). Prevalensi Pediculosis pada anak yang tidur sendiri lebih rendah dibandingkan anak yang tidur bersama anggota keluarga lain. Hal ini dapat terjadi karena murid yang tertular Pediculosis dari teman sekolahnya menularkannya pada anggota keluarga di rumah. Sebaliknya, anak yang terinfestasi dapat menularkan Pediculosis pada teman sekolahnya. Hal ini disebabkan pada waktu tidur terjadi kontak langsung antara kepala dengan kepala atau dengan perantara bantal, sprei dan alat-alat tidur.

Responden yang sering meminjam aksesoris rambut (sisir, jepitan, bando, ikat rambut) merupakan yang tertinggi mengalami Pediculosis yaitu sebesar 12,1\% (15 dari 33 responden). Salah satu faktor penularan kutu rambut yaitu dengan kontak tidak langsung (melalui benda) yang dipakai bersama yang telah terkontaminasi morfologi kutu rambut (kutu dewasa, nimfa ataupun telur). Menggunakan sisir atau aksesoris rambut bersama (pada keadaan menggunakan sisir secara bersamaan) akan membuat telur bahkan kutu dewasa menempel pada sisirsehingga akan tertular, begitu juga dengan aksesoris rambut seperti kerudung, bando dan pita (Hardiyanti et al., 2015). 
Pediculosis pada anakdapat dikurangi/ dihilangkan dengan cara meningkatkan kualitas kebersihan diri pada masing-masing individu terutama lebih memperhatikan kebersihan rambut dan menjaga kebersihan rambut atau tidak memiliki rambut yang panjang dan memotong rambut minimal 2 kali setahun.

\section{KESIMPULAN}

Persentase Pediculosis capitis pada anak SD di Desa Cempaka Banjarbaru sebesar $19,87 \%$, dengan personal hygiene kategori baik sebesar $48 \%$ dan kategori kurang baik sebesar $52 \%$. Secara statistik terdapat hubungan antara Pediculosis capitis dengan personal hygiene pada anak SD di Desa Cempaka Banjarbaru.

\section{SARAN}

Disarankan agar memperhatikan dan meningkatkan personal hygiene, khususnya kebersihan rambut sehingga penyebab penularan kutu kepala (Pediculosis capitis) dapat dihilangkan serta menghindari pemakaian alat pribadi secara bersama-sama seperti sisir, kerudung, aksesoris rambut, pakaian, bantal dan sebagainya. Dinas kesehatan bersama guru dan orang tua agar mengedukasi serta mengawasi faktor personal hygiene tersebut.

\section{DAFTAR PUSTAKA}

Alatas, S. S. . (2013). Hubungan Tingkat Pengetahuan Mengenai Pedikulosis Kapitis dengan Karakteristik Demografi Santri Pesantren X, Jakarta Timur. EJournal Kedokt. Indones, 53-57.

Ansyah, A. . (2013). Hubungan antara Personal Hygiene dengan Angka Kejadian Pediculosis Capitis pada Santri Putri Pondok Pesantren Modern Islam Assalaam Surakarta. Universitas Muhammadiyah Surakarta.

Borges-Moroni R, Mendes, J., Justiniano, S. C. ., \& Bindá, A. G. . (2011). Head lice infestation in children in day-care centers and schools of Manaus, Amazon, Brazil. Rev Patol Trop, 40, 263-270.

Guenther, L. C. . (2015). Pediculosis and pthiriasis (lice infestation). Medscape.

Gulgun M, Balci, E., Karaoglu, A., Babacan, O., \& Türker, T. (2013). Pediculosis capitis: prevalence and its associated factors in primary school children living in rural and urban areas in Kayseri, Turkey. Cent.
Eur. J. Public Health, 21, 104.

Hardiyanti, N. ., Kurniawan, B., Mutiara, H., \& Suwandi, J. . (2015). Penatalaksanaan Pediculosis capitis. J. Major, 4, 47-52.

Madke, B., \& Khopkar, U. (2012). Pediculosis capitis: An update. Indian J. Dermatol. Venereol. Leprol, 78, 429.

Munusamy, H., Murhandarwati, E. E. ., \& Umniyati, S. . (n.d.). The Relationship Between The Prevalence of Head Lice Infestation with Hygiene and Knowledge Among The Rural School Children In Yogyakarta. Trop. Med. J., 1.

Saputri, Y. ., \& Suryani, S. (2017). Hubungan Personal Hygiene Dengan Kejadian Pediculus Humanus Capitis Pada Anak Usia Sekolah Di Sd Negeri 1 Bendungan Kabupaten Temanggung. Universitas Aisyiyah Yogyakarta.

Wolff, K., Goldsmith, L., Katz, S., Gilchrest, B., Paller, A. ., Leffell, D., \& Paller, A. (2008). Fitzpatrick's dermatology in general medicine.

Zhen, A. J. L. ., Murhandarwati, E. E. ., \& Umniyati, S. . (n.d.). Head Lice Infestation and Its Relationship with Hygiene and Knowledge among Urban School Children in Yogyakarta. Trop. Med. J, 1. 